
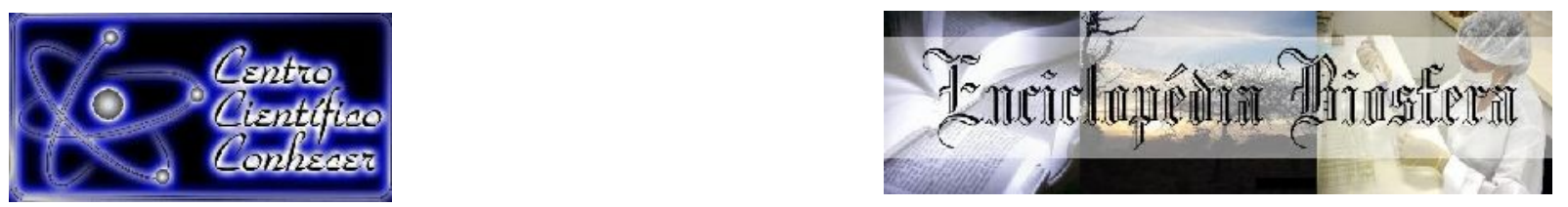

\title{
ANCORAGEM MOLECULAR DE FÁRMACOS E DERIVADOS COM PROTEÍNAS DA Mycobacterium tuberculosis
}

\author{
Igor Batista Sales ${ }^{1}$; Francielly Carvalho de Oliveira ${ }^{2}$; Ciro Ribeiro Filadelfo ${ }^{3}$ \\ ${ }^{1}$ Farmacêutico Graduado pela Faculdade Maria Milza - FAMAM \\ ${ }^{2}$ Mestre em Ciências Agrárias pela Universidade Federal do Recôncavo da Bahia - UFRB \\ ${ }^{3}$ Professor da área de Bioquímica dos cursos de farmácia e biomedicina pela Faculdade Maria \\ Milza - FAMAM, Rodovia BR-101 - Km 215 - Governador Mangabeira / BA \\ E-mail: cirorfiladelfo@gmail.com \\ Recebido em: 15/08/2021 - Aprovado em: 15/09/2021 - Publicado em: 30/09/2021 \\ DOI: 10.18677/EnciBio_2021C3 \\ trabalho licenciado sob licença Creative Commons Attribution-NonCommercial-NoDerivatives 4.0 International License.
}

\begin{abstract}
RESUMO
A tuberculose $(\mathrm{Tb})$ é uma doença infectocontagiosa que acomete os pulmões, causada pelo bacilo Mycobacterium tuberculosis (MTb), e atinge um terço da população mundial. Nos últimos anos o MTb tem apresentado resistências aos fármacos antituberculose (anti-Tb). Uma alternativa viável para acelerar o processo de estudos para potenciais drogas é a utilização da bioinformática por meio do docking molecular (DM). Assim, o objetivo deste trabalho foi propor ligantes alternativos aos fármacos conhecidos a partir do uso de DM. Os compostos testados foram obtidos na base de dados PubChem/ZINC. Os aminoácidos dos sítios ativos das proteínas de interesse foram definidos a partir de proteínas já descritas. Os resultados destes estudos mostraram-se vantajosos para alguns compostos, rifampicina e derivados de isoniazida, os quais apresentaram-se com maior afinidade que as drogas usualmente utilizadas com destaque para a rifampicina, pois, foram obtidos valores de $-8,7 \mathrm{kcal} / \mathrm{mol} \mathrm{com}$ a catalase peroxidase (padrão isoniazida), $-6,5 \mathrm{kcal} / \mathrm{mol}$ para a proteína ribossomal S1 (padrão ácido pirazinóico) e com a arabinosil transferase, $-9,3 \mathrm{kcal} / \mathrm{mol}$ (padrão etambutol). Desta forma, a rifampicina e os derivados da isoniazida futuramente, poderão contribuir para os estudos in vivo e in vitro de novas abordagens quimioterápicas contra o Mtb, de forma isolada ou associada.
\end{abstract}

PALAVRAS-CHAVE: Biologia computacional; Ligantes; Mycobacterium tuberculosis.

\section{MOLECULAR ANCHORAGE OF DRUGS AND DERIVATIVES WITH PROTEINS FROM Mycobacterium tuberculosis}

\footnotetext{
ABSTRACT

Tuberculosis (Tb) is an infectious disease that affects the lungs, caused by the bacillus Mycobacterium tuberculosis (MTb), and affects one third of the world's population.. In recent years, MTb has shown resistance to anti-tuberculosis (anti-Tb) drugs. A viable alternative to speed up study process for potential drugs is use of bioinformatics through molecular docking (DM). Thus, aim of this work was to propose alternative ligands to drugs known from use of DM. Tested compounds were obtained from PubChem/ZINC database. The amino acids of active sites proteins interest were defined from previously ENCICLOPÉDIA BIOSFERA, Centro Científico Conhecer - Jandaia-GO, v.18 n.37; p. 32 2021
} 
described proteins. The results these studies proved to be advantageous for some compounds, rifampicin and isoniazid derivatives, which presented with greater affinity than commonly used drugs, especially rifampicin, as we obtained values of $-8.7 \mathrm{kcal} / \mathrm{mol}$ with catalase peroxidase (isoniazid standard), $-6.5 \mathrm{kcal} / \mathrm{mol}$ for ribosomal protein $\mathrm{S1}$ (pyrazinoic acid standard) and with arabinosyl transferase, $-9.3 \mathrm{kcal} / \mathrm{mol}$ (ethambutol standard). Thus, rifampicin and isoniazid derivatives in future may contribute to in vivo and in vitro studies of new chemotherapeutic approaches against Mtb, alone or in association.

KEYWORDS: Computational biology; Ligands; Mycobacterium tuberculosis.

\section{INTRODUÇÃO}

A tuberculose (Tb) é uma doença infectocontagiosa e mortal que geralmente acomete os pulmões, causada pelo bacilo Mycobacterium tuberculosis (MTb) também conhecido por bacilo de Koch. Acredita-se que cerca de um terço da população mundial apresente essa bactéria de forma inativa no organismo (infecção latente) (OMS, 2016; BARBERIS et al., 2017).

Apenas no ano de 2016 foram constatados 10,4 milhões de novos casos e cerca de 10,7 milhões de mortes provenientes da doença, sendo que $90 \%$ dos casos ocorreram em países não desenvolvidos, sem planejamento de saúde. Em 2017, foram constatados 10 milhões de casos incidentes de $\mathrm{Tb}$ e 1,6 milhões de óbitos, apresentando respectivamente $1,8 \%$ e $3,9 \%$ de redução de casos se comparado ao ano de 2016 (OMS, 2018; CDC, 2019).

De acordo com o Ministério da Saúde (BRASIL, 2019), o Brasil está entre os 30 países de alto índice de Tb, em 2017 foram diagnosticados cerca de 72,7 mil casos novos da doença, com incidência de 10,0 a 74,7 casos por 100 mil habitantes e taxa de 4,48 mil óbitos (2,2 por 100 mil habitantes).

O tratamento anti-Tb é feito por meio de medicamentos antibióticos aprovados e fornecidos pelo Food and Drug Administration (FDA) dos Estados Unidos - EUA e também pelo Ministério da Saúde (MS). São utilizados Isoniazida, rifampicina, etambutol e ácido pirazinóico, administrados durante dois meses, que consiste em uma fase intensiva, seguida da fase de continuação, a qual pode durar entre quatro ou sete meses (CDC, 2016). O abandono ou administração incorreta do tratamento promove um aumento significativo no número de casos de MTb resistente, assim como efeitos colaterais (OMS, 2011; BRASIL, 2019)Em 2016 foi reportado pelo Ministério da Saúde) que houve eficácia da quimioterapia de $74,6 \%$, em casos com registros laboratoriais, porém, com 10,8\% de evasão e 4,1\% sem desfecho(BRASIL, 2019).

Uma alternativa viável para acelerar o processo de estudos para potenciais fármacos anti-Tb é a utilização do acoplamento molecular para análise de possíveis proteínas interativas presentes no sistema biológico de MTb, e assim, descobrir possíveis alvos quimioterápicos (SHARMA; BISHT, 2017).

Diante do exposto, o presente estudo teve como objetivo propor ligantes alternativos para os alvos moleculares proteicos que apresentam interações com fármacos conhecidos no tratamento anti-Tb, bem como ampliar o conhecimento dos mecanismos de ação destas drogas. 


\section{MATERIAL E MÉTODOS}

Para esse estudo foram buscadas as estruturas tridimensionais das proteínas no PDB (Protein Data Bank-http://rcsb.org). A estrutura 2D dos compostos foram obtidas nas bases de dados PubChem (http://pubchem.ncbi.nlm.nih.gov) e ZINC (STERLING; IRWIN, 2015), e salva em 3D no formato .pdb usando o programa MarvinSketch (https://chemaxon.com/products/marvin).

Neste estudo foi comparado a capacidade de interação de algumas proteínas presentes na estrutura do MTb com fármacos utilizados no tratamento da Tb. As proteínas em questão foram: catalase-peroxidase (Código PDB: 1SJ2); a proteína ribossomal S1 (Código PDB: 4NNI); e a arabinosil transferase (Código PDB: 7BVF). Os fármacos e derivados foram: isoniazida (PubChem CID 3767); piruvato de isoniazida (ZINC4974291); glucuronato de isoniazida (ZINC4539129); ácido alfa-cetoglutárico de isoniazida (ZINC30731295); rifampicina (ZINC95544552); etambutol (ZINC19364219) e ácido pirazinóico (PubChem CID 1047) sobre essas proteínas.

Os aminoácidos dos sítios ativos das proteínas de interesse foram definidos a partir dos trabalhos: catalase-peroxidase (SRIVASTAVA et al., 2017); proteína ribossomal S1 (YANG et al., 2015); arabinosil transferase (ZHANG, 2020), estas foram selecionadas por apresentar uma única cadeia. Abriu-se os arquivos, baixados pelo PDB, no WordPad, e foi excluído os complementos "HETATM" e "CONECT".

O AutoDockTools 1.5.6 (SANNER et al., 1996) foi utilizado para preparar as moléculas de ligantes e os receptores, convertidas para o formato .pdbqt, que logo seriam utilizadas nos cálculos de acoplamento e também preparo do arquivo de configuração (conf) com as coordenadas da grid box, ajustada ao sítio ativo. Logo após, o docking molecular foi executado com o programa Autodock Vina (TROTT \& OLSON, 2010).

O programa PyMol Molecular Graphics System versão 2.3.3, Schrödinger, LLC, foi utilizado para verificar o complexo ideal considerando todos os aspectos estereoquímicos. Em seguida, foi utilizado o Discovery Studio v20.1.0.19295 (BIOVIA, 2019) para visualização do diagrama 2D e 3D.

\section{RESULTADOS E DISCUSSÃO ANCORAGENS MOLECULARES DE LIGANTES COM CATALASE-PEROXIDASE}

A catalase-peroxidase é alvo de vários estudos que visam encontrar um tratamento mais eficiente para Tb. Ao inibir essa enzima, ocorre um desequilíbrio no status redox do MTb, causando desestruturação de membranas devido a peroxidação lipídica e consequentemente morte celular (UNISSA et al., 2016). Desta forma, foi realizado o acoplamento molecular entre essa estrutura alvo e diferentes ligantes, incluindo a isoniazida (droga padrão), alguns dos seus derivados, bem como outros fármacos que são comercializados contra a Tb (Quadro 1).

Foram observados que alguns desses derivados apresentaram maior afinidade com a proteína do que a própria isoniazida. Além disso, a rifampicina apresentou afinidade de $-7,8 \mathrm{kcal} / \mathrm{mol}$, mostrando-se como um forte candidato para estudos de associações quimioterápicas. 
QUADRO 1: Resultado dos melhores complexos gerados a partir da combinação da estrutura cristalina de catalase-peroxidase com drogas. Abaixo estão os valores de afinidade das melhores posições.

\begin{tabular}{|r|c|}
\hline \multicolumn{1}{|c|}{ Ligante } & $\begin{array}{c}\text { AFINIDADE } \\
(\mathrm{kcal} / \mathrm{mol})\end{array}$ \\
\hline Isoniazida & $-5,8 \mathrm{kcal} / \mathrm{mol}$ \\
\hline Piruvato de isoniazida & $-6,4 \mathrm{kcal} / \mathrm{mol}$ \\
\hline Ácido alfa cetoglutárico de isoniazida & $-7,4 \mathrm{kcal} / \mathrm{mol}$ \\
\hline Rifampiazida & $-6,6 \mathrm{kcal} / \mathrm{mol}$ \\
\hline Ácido pirazinóico & $-7,8 \mathrm{kcal} / \mathrm{mol}$ \\
\hline Etambutol & $-5,1 \mathrm{kcal} / \mathrm{mol}$ \\
\hline & $-5,4 \mathrm{kcal} / \mathrm{mol}$ \\
\hline
\end{tabular}

Por meio dos diagramas 2D e 3D foi possível observar os tipos de interações/ligações do sítio ativo do receptor enzimático com a isoniazida e rifampicina (Figuras 1A e 1B).

Mesmo a isoniazida $(-5,8 \mathrm{kcal} / \mathrm{mol})$ apresentando uma das menores afinidade, exceto quando comparada a ácido pirazinóico $(-5,1 \mathrm{kcal} / \mathrm{mol})$ e ao etambutol $(-5,4$ $\mathrm{kcal} / \mathrm{mol}$ ), o resultado da primeira é maior que de outros trabalhos, como de Prakash et al. (2017) para catalase selvagem com $-4,05 \mathrm{kcal} / \mathrm{mol}$ e $-4,81 \mathrm{kcal} / \mathrm{mol}$, da catalase mutante, e de Srivastava et al. (2017), para catalase selvagem de $-4,81$ até $-5,69$ $\mathrm{kcal} / \mathrm{mol}$ e mutante de $-4,67$ até $-4,72 \mathrm{kcal} / \mathrm{mol}$, neste último trabalho em sítios distintos da proteína.

De acordo com as figuras abaixo é evidente a diferença das características das interações entre o alvo quimioterápico e os fármacos analisados. Segundo Kollman e Allen (1972), a respeito da natureza das ligações de hidrogênio, uma dessas é a maior região aceptora de densidade eletrônica da rifampicina no sítio catalítico da catalase peroxidase, quando comparado ao fármaco padrão, na ligação de hidrogênio (região em verde da imagem 3D da Figura 1). Além disso, no contexto com a rifampicina, apresentou ligação de hidrogênio, ligação intermolecular forte, diferente do contexto com a droga padrão, bem como o número de aminoácidos envolvidos na ligação (imagem 2D das figuras $1 \mathrm{~A}$ e $1 \mathrm{~B}$ ). Assim, a partir destas observações, é possível compreender a maior afinidade da rifampicina.

De forma inédita apresenta-se o glucuronato de isoniazida e o piruvato de isoniazida com características da ancoragem molecular semelhantes a rifampicina, com um número de aminoácidos interagindo com o sítio catalítico da catalase-peroxidase maior que do medicamento padrão e região aceptora maior de densidade eletrônica (ligação de hidrogênio) destes derivados, porém, naturalmente menor nesses dois aspectos quando comparados a rifampicina.

É compreensível, a partir do raciocínio traçado inicialmente, que à medida que reduz essa região aceptora, o número de aminoácidos envolvidos e tipos de ligações intermoleculares mais intensas, aumenta a energia livre de ligação e, por conseguinte, reduz a afinidade (TAO et al., 2020). É o caso dos resultados inéditos dos derivados ácido alfa cetoglutárico de isoniazida e piruvato de isoniazida, em seguida, as outras drogas usuais anti-Tb (etambutol e ácido pirazinóico, respectivamente), a partir das observações oriundas das imagens $2 \mathrm{D}$ e $3 \mathrm{D}$ produzidas de todos os derivados e fármacos utilizados neste estudo (dados não apresentados) e do Quadro 1. 
FIGURA 1: Visualização 2D e 3D da interação entre a estrutura-cristalina de Visualização 2D e 3D da (A: catalase-peroxidase e isoniazida); (B: catalase-peroxidase e rifampicina) e a nuvem eletrostática da interação do receptor com o ligante.

A

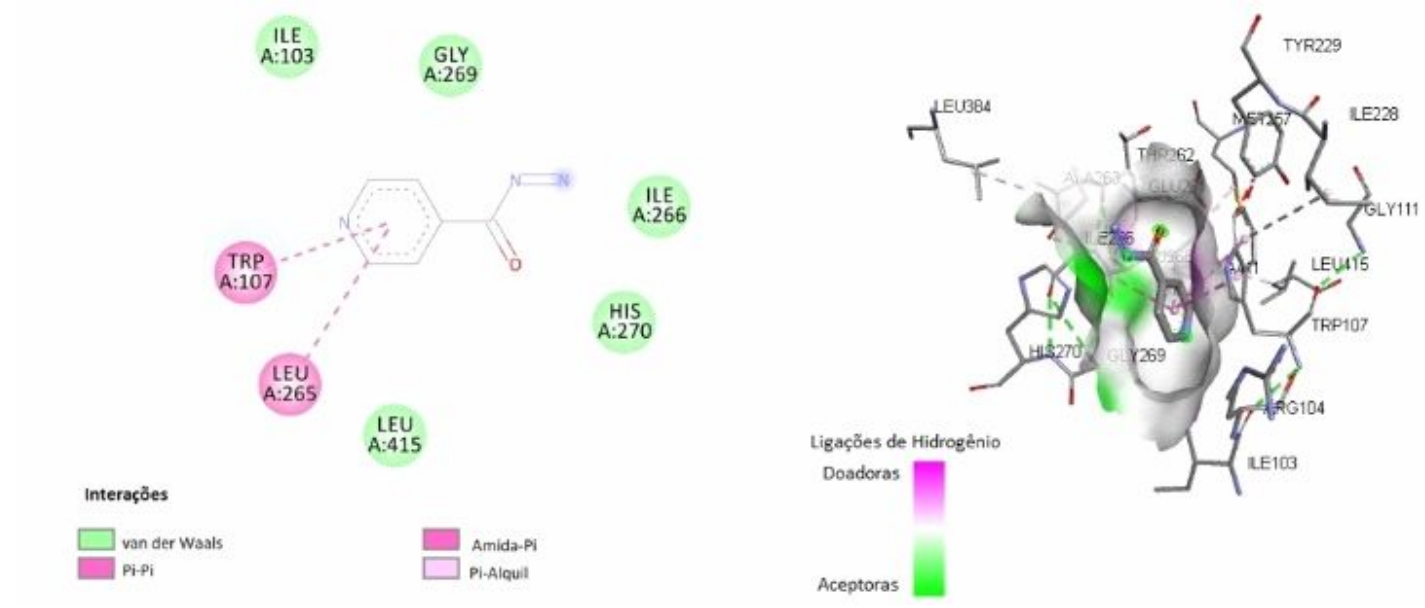

B

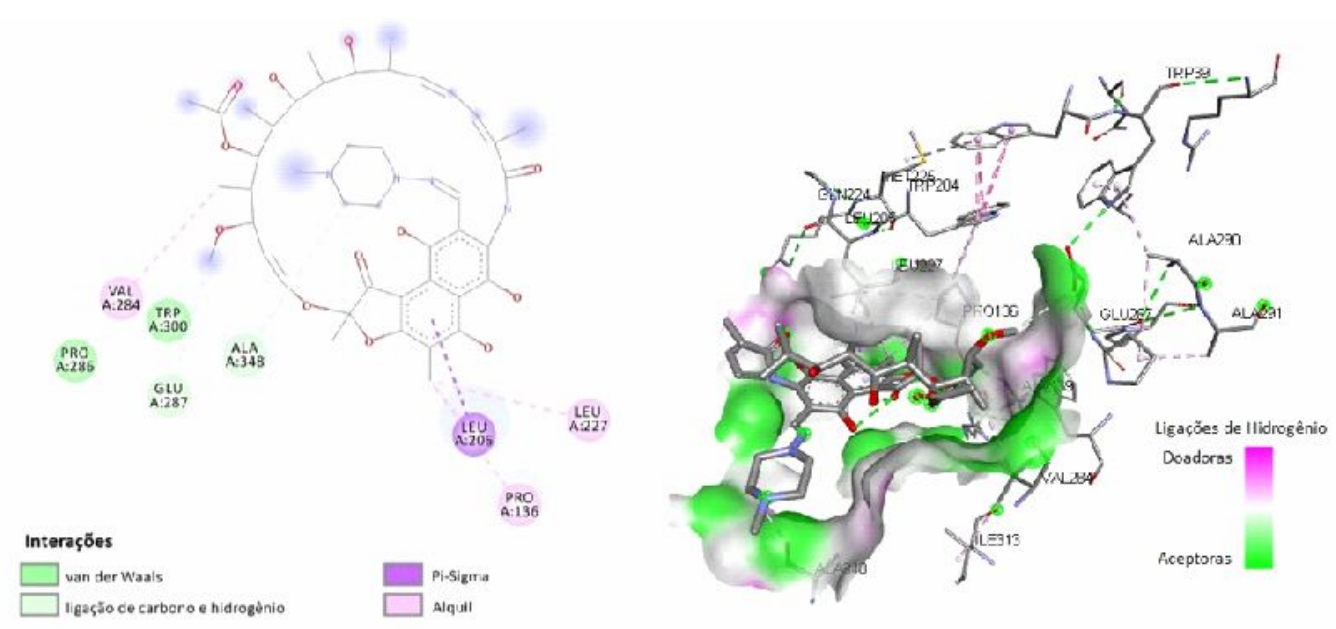

\section{ANCORAGENS MOLECULARES DE LIGANTES COM PROTEÍNA RIBOSSOMAL S1 \\ (RpsA)}

A proteína ribossomal S1 de MTb é uma molécula que tem como ligante principal o ácido pirazinóico, forma ativa da pirazinamida. Como já descrito, a resistência à pirazinamida é causada por mutações no PncA, gene codificador da pirazinamidase que está envolvida na conversão da droga em ácido pirazinóico (DILLON et al., 2017).

Ancoragens moleculares foram realizadas com essa proteína e com os mesmos ligantes apresentados anteriormente, conforme os resultados exibidos no Quadro 2. 
QUADRO 2: Resultado dos melhores complexos gerados a partir da combinação da proteína ribossomal S1 com drogas. Abaixo estão os valores de afinidade das melhores posições.

\begin{tabular}{|r|c|}
\hline \multicolumn{1}{|c|}{ Ligante } & $\begin{array}{c}\text { AFINIDADE } \\
(\mathrm{kcal} / \mathrm{mol})\end{array}$ \\
\hline Ácido pirazinóico & $-3,5 \mathrm{kcal} / \mathrm{mol}$ \\
\hline Isoniazida & $-3,4 \mathrm{kcal} / \mathrm{mol}$ \\
\hline Piruvato de isoniazida & $-4,3 \mathrm{kcal} / \mathrm{mol}$ \\
\hline Alucuronato de isoniazida & $-4,1 \mathrm{kcal} / \mathrm{mol}$ \\
\hline Écido alfa cetoglutárico de isoniazida & $-3,5 \mathrm{kcal} / \mathrm{mol}$ \\
\hline Rifampicina & $-6,2 \mathrm{kcal} / \mathrm{mol}$ \\
\hline Etambutol & $-2,5 \mathrm{kcal} / \mathrm{mol}$ \\
\hline
\end{tabular}

Conforme mostrado no Quadro 2, o DM da proteína ribossomal S1 com o ácido pirazinóico apresentou baixa afinidade, exceto quando comparado ao etambutol. O DM do ácido pirazinóico quando comparado a outros trabalhos, como de Khan et al. (2019) para a proteína selvagem $(-6,88 \mathrm{kcal} / \mathrm{mol})$ e a mutante (de $-3,4$ até $-4,62 \mathrm{kcal} / \mathrm{mol})$, obteve um resultado maior apenas para um dos sítios dessa última variante da proteína.

O ácido pirazinóico e a isoniazida são drogas que apresentam similaridades em suas estruturas químicas. Desta forma, foi feito o estudo de DM da isoniazida e seus derivados com a proteína ribossomal S1. O Quadro 2 mostra que o atracamento entre a isoniazida e a proteína ribossomal $\mathrm{S} 1$ gerou maior energia livre de ligação $(-3,4$ $\mathrm{kcal} / \mathrm{mol}$ ), assim menor afinidade quando comparado ao contexto do ácido pirazinóico. Porém, os derivados (ácido alfa cetoglutárico de isoniazida, glucuronato de isoniazida e piruvato de isoniazida), apresentaram afinidades maiores $(-3,5 \mathrm{kcal} / \mathrm{mol},-4,1 \mathrm{kcal} / \mathrm{mol} \mathrm{e}$ $-4,3 \mathrm{kcal} / \mathrm{mol}$, respectivamente), exceto para o primeiro derivado que foram obtidos valores equivalentes.

Quanto à rifampicina essa teve melhor afinidade à proteína ribossomal $\mathrm{S} 1$, apesar de apresentar uma grande semelhança nos tipos de ligações, quando comparado ao ácido pirazinóico, porém, seguindo o raciocínio anteriormente colocado, um dos fatores que pode auxiliar no entendimento da maior afinidade, consiste no número de aminoácidos que interagem ao alvo quimioterápico, como encontrado em nossos resultados (Figura 2 A e B, ambas 2D). Além disso, consequentemente, o número das regiões aceptoras das densidades eletrônicas envolvidas nas ligações de hidrogênio, região em verde nas imagens $3 \mathrm{D}$ tanto da figura $3 \mathrm{~A}$ como da $3 \mathrm{~B}$, está em maior quantidade na proteína em questão interagindo com a rifampicina, quando comparada ao contexto com o fármaco padrão. 
FIGURA 2: Visualização 2D e 3D da (A: proteína ribossomal S1 e ácido pirazinóico); (B: proteína ribossomal $\mathrm{S} 1$ e rifampicina) e a nuvem eletrostática da interação do receptor com o ligante.

A
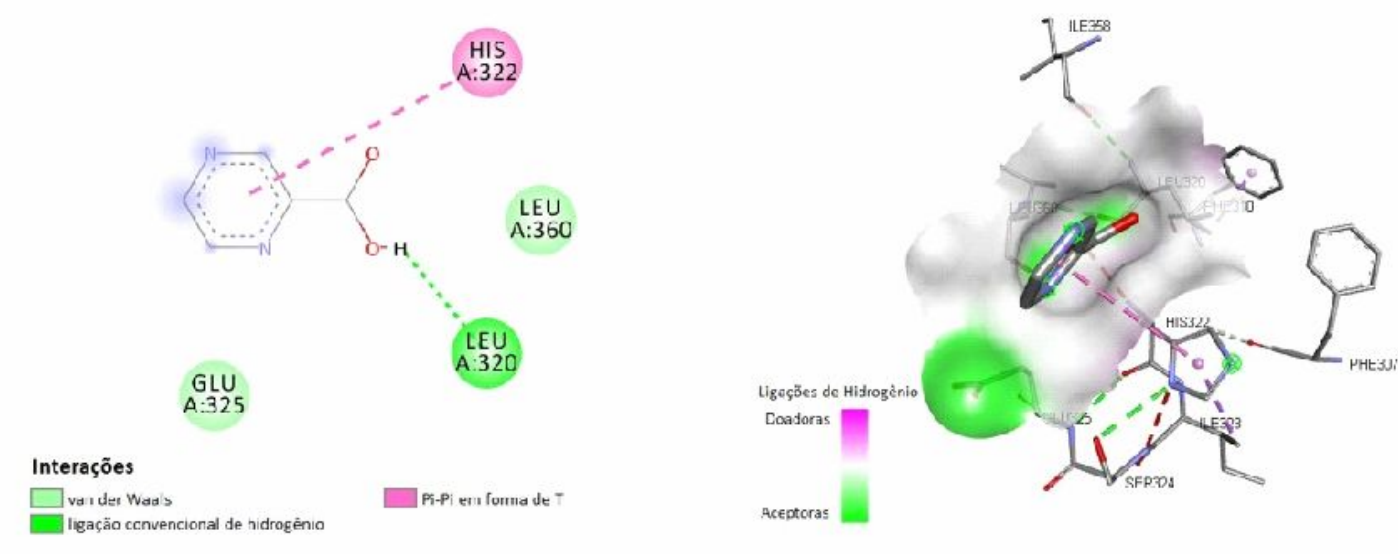

B

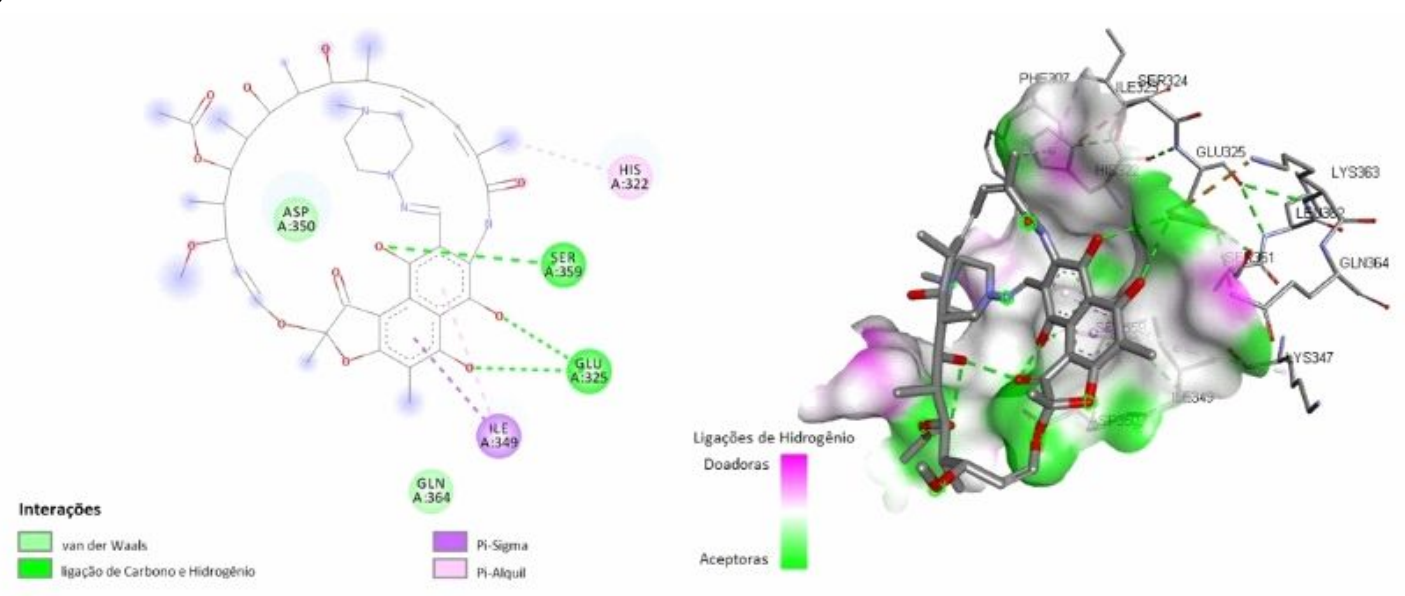

ANCORAGEM MOLECULAR DO ARABINOSIL TRANSFERASE COM ETAMBUTOL

A arabinosil transferase é uma enzima do MTb, capaz de sintetizar a arabinogalactano, componente fundamental da parede celular dessas bactérias (ZHANG, 2020). Por meio da simulação de DM entre a arabinosil transferase e o etambutol, foi obtido o valor de $-4,6 \mathrm{kcal} / \mathrm{mol}$, correspondente à afinidade, desta forma, ao ocorrer a interação entre a enzima e o ligante em questão, este poderá interferir na biossíntese de peptídeoglicanos do M. tuberculosis (ZHANG, 2020). Outros ligantes (isoniazida: $-4,8 \mathrm{kcal} / \mathrm{mol}$; ácido pirazinóico: $-4,1 \mathrm{kcal} / \mathrm{mol}$ e glucuronato de isoniazida: $6,3 \mathrm{kcal} / \mathrm{mol}$ ) foram testados por ancoragem molecular com a arabinosil transferase, $\mathrm{e}$ apresentaram afinidades maiores que a droga padrão, exceto para o ácido pirazinóico. Além desses, a rifampicina apresentou afinidade ainda maior, -9,3 kcal $/ \mathrm{mol}$, demonstrado no Quadro 3. 
QUADRO 3: Resultado dos melhores complexos gerados a partir da arabinosil transferase com fármacos e derivados. Abaixo estão os valores de afinidade das melhores posições.

\begin{tabular}{|r|c|}
\hline \multicolumn{1}{|c|}{ Ligante } & $\begin{array}{c}\text { AFINIDADE } \\
(\mathrm{kcal} / \mathrm{mol})\end{array}$ \\
\hline Etambutol & $-4,6 \mathrm{kcal} / \mathrm{mol}$ \\
\hline Isoniazida & $-4,8 \mathrm{kcal} / \mathrm{mol}$ \\
\hline Piruvato de isoniazida & $-6,0 \mathrm{kcal} / \mathrm{mol}$ \\
\hline Ácido alfa cetoglutárico de isoniazida & $-6,3 \mathrm{kcal} / \mathrm{mol}$ \\
\hline Rifampiazida & $-5,6 \mathrm{kcal} / \mathrm{mol}$ \\
\hline Ácido Pirazinóico & $-9,3 \mathrm{kcal} / \mathrm{mol}$ \\
\hline & $-4,1 \mathrm{kcal} / \mathrm{mol}$ \\
\hline
\end{tabular}

A afinidade do etambutol $(-4,6 \mathrm{kcal} / \mathrm{mol})$, quando comparada com a mesma ancoragem realizada por Das et al., (2020), com $-4,52 \mathrm{kcal} / \mathrm{mol}$, o nosso resultado foi bem próximo.

Diferente do resultado para o alvo quimioterápico anterior (proteína ribossomal S1), o número de aminoácidos da droga padrão que interage com a enzima é maior que o da rifampicina, bem como há uma semelhança nos tipos da maioria das ligações nos dois contextos de interação (imagens 2D tanto da figura $3 \mathrm{~A}$ e B), porém, o número e 0 tamanho das regiões aceptoras das densidades eletrônicas (região em verde nas imagens 3D) foram maiores com a rifampicina, quando comparado ao etambutol. Assim, podendo ser, nessa situação, a característica que definiu a maior afinidade da arabinosil transferase à rifampicina.

FIGURA 3: Visualização 2D e 3D da (A: Arabinosil transferase e etambutol); (B: Arabinosil transferase e rifampicina) e a nuvem eletrostática da interação do receptor com o ligante.

A

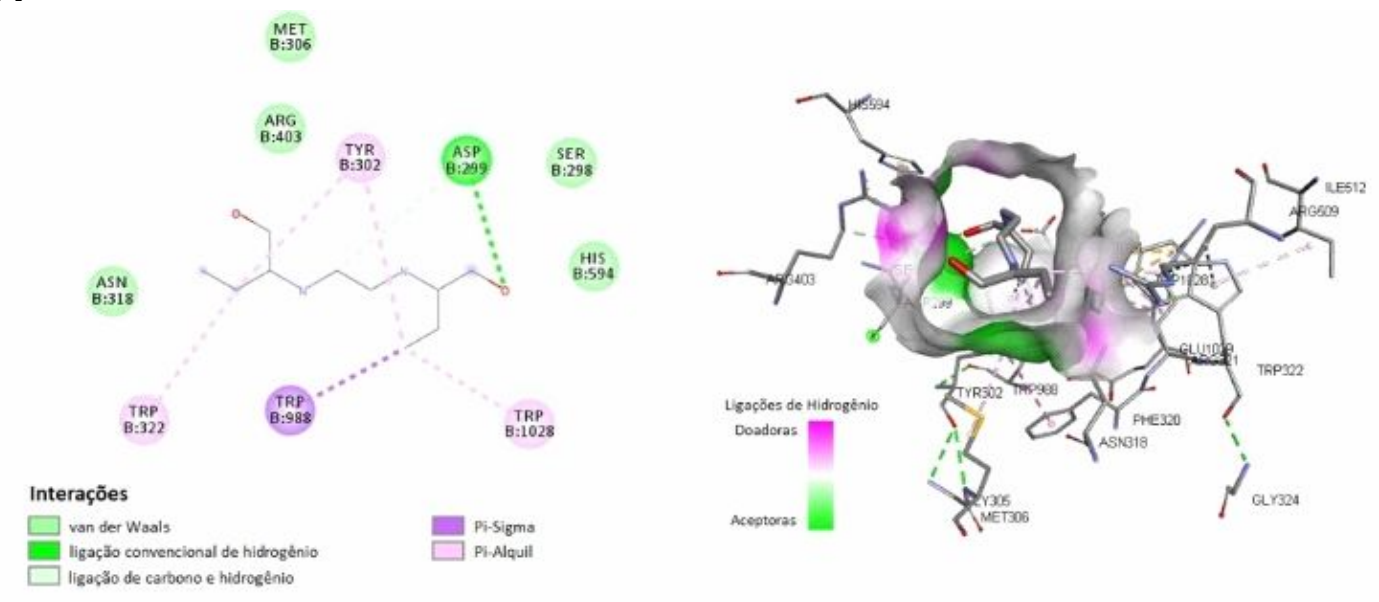


B

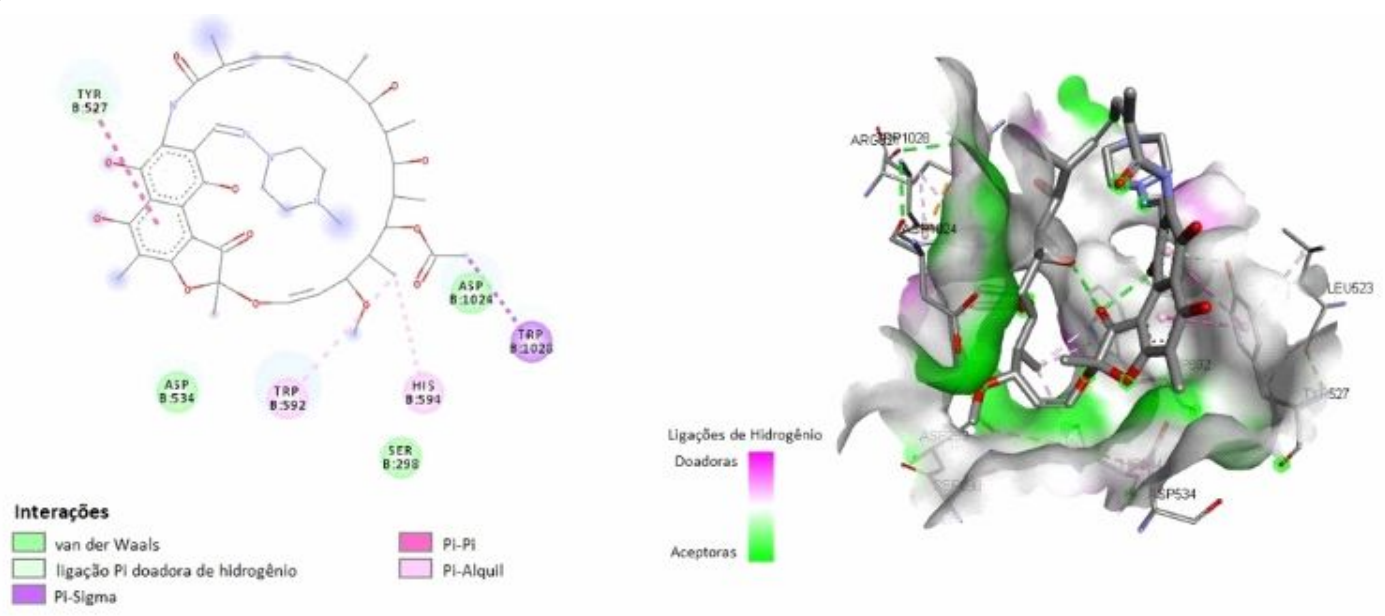

\section{AFINIDADE TOTAL OBTIDA POR MEIO DA ANÁLISE POR ANCORAGENS MOLECULARES}

Como pode ser visto no Gráfico 1, alguns ligantes mostraram-se bastante eficientes na interação com as proteínas alvos, tendo em vista alguns valores altamente negativos, logo com maior afinidade, como a catalase peroxidase com glucuronato de isoniazida apresentando $-7,4 \mathrm{kcal} / \mathrm{mol}$, a catalase peroxidase com piruvato de isoniazida apresentando $-6,4 \mathrm{kcal} / \mathrm{mol}$ e a catalase peroxidase com ácido alfacetoglutárico de isoniazida, apresentando $-6,6 \mathrm{kcal} / \mathrm{mol}$.

A rifampicina é um fármaco antibiótico de primeira escolha importante para tratamento da tuberculose, age induzindo diversas enzimas que metabolizam drogas, a exemplo do CYP3A4 (NIEMI et al., 2003). Todas as ancoragens moleculares com essa droga obtiveram maiores afinidades para todas as proteínas analisadas neste trabalho, quando comparado a todas as outras, principalmente, para o acoplamento com arabinosil transferase com energia livre de ligação de $-9,3 \mathrm{kcal} / \mathrm{mol}$. Estes resultados evidenciam a necessidade de mais estudos com associações quimioterápicas envolvendo a rifampicina, devido à versatilidade dessa droga em interagir fortemente com várias proteínas do patógeno, bem como os derivados de isoniazida, que foi apresentado de forma inédita e foram obtidos resultados promissores, vale ressaltar, melhores que as drogas padrões em todas as situações avaliadas, com o intuito científico de contornar a resistência do bacilo. 
GRÁFICO 1: Melhores afinidades obtidas por meio de DM.

Maiores afinidades obtidas por Dockings

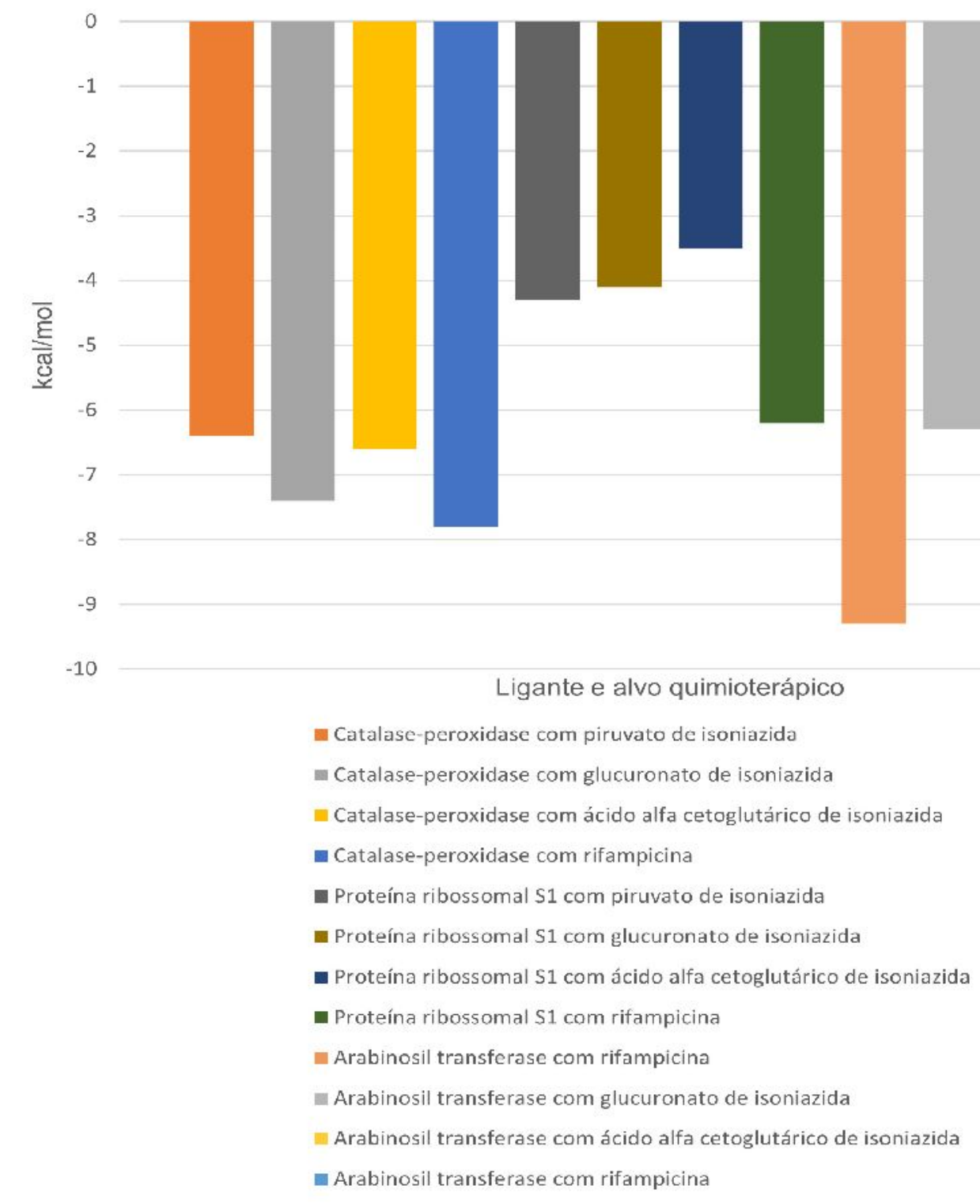

\section{CONCLUSÕES}

Os resultados destes estudos mostraram-se bastante vantajosos para alguns compostos (piruvato de isoniazida, glucuronato de isoniazida e ácido alfa cetoglutárico de isoniazida), alguns apresentaram maior afinidade que as drogas comercializadas, exceto para a rifampicina. Desta forma, esses compostos podem futuramente contribuir para o desenvolvimento de novas quimioterapias que se apresentem mais eficientes contra o M. tuberculosis.

Foi possível observar as interações ocorridas entre o ligante e o seu alvo, identificando grupos de aminoácidos funcionais que possibilitaram ligações favoráveis, 
e a partir disso, estudar ajustes na estrutura química do fármaco afim de potencializar sua ação.

A maioria das ligações/interações testadas entre proteínas e ligantes foram ligações convencionais de hidrogênio, de carbono-hidrogênio, não covalentes e força de Van der Waals. Assim, esses derivados poderão ser usados em estudos in vitro e in vivo de forma isolada e/ou associadas com rifampicina contra a $M$. tuberculosis, podendo apresentar efeitos sinérgicos ou aditivos, bem como reduzir as chances de casos refratários.

Devido a pandemia não foi possível realizar pesquisas in vitro e in vivo com os achados desse estudo, bem como o elevado custo para a execução de tais procedimentos, fato relacionado ao contexto atual acadêmico/científico do país.

\section{REFERÊNCIAS}

BARBERIS, I.; BRAGAZZI, N. L.; GALLUZZO, L. \& MARTINI, M. The history of tuberculosis: From the first historical records to the isolation of Koch's bacillus. Journal of Preventive Medicine and Hygiene, v. 58, n. 1, p. 9-12, 2017. Disponível em: <https://www.ncbi.nlm.nih.gov/pmc/articles/PMC5432783/>.

BIOVIA, D.S.; Discovery Studio Visualizer, v20.1.0.19295, San Diego: Dassault Systèmes, 2019.

BRASIL. Ministério da Saúde. Manual de Recomendações para o Controle da Tuberculoe no Brasil, 2a Edição Atualizada, Brasília: Ministério da Saúde, 364 p., $2019 . \quad$ Disponível em: <https://bvsms.saude.gov.br/bvs/publicacoes/manual_recomendacoes_controle_tubercu lose_brasil_2_ed.pdf>.

Centers for Disease Control and Prevention. Global Epidemiology of Tuberculosis and Progress Toward Achieving Global Targets - 2017. 2019. Disponível em: <https://www.cdc.gov/mmwr/volumes/68/wr/mm6811a3.htm>. Acesso em: 15 jun. 2020.

Centers for Disease Control and Prevention. Treatment for TB Disease. 2016. Disponível em: <https://www.cdc.gov/tb/topic/treatment/tbdisease.htm>. Acesso em: 20 set. 2016.

DAS, N.; JENA, P. K. \& PRADHAN, S. K. Arabinosyltransferase C enzyme of Mycobacterium tuberculosis, a potential drug target: An insight from molecular docking study. Heliyon, v. 6, n. 2, p. e02693, 2020. Disponível em: <https://www.sciencedirect.com/science/article/pii/S2405844019363534>. doi: 10.1016/j.heliyon.2019.e02693.

DILLON, N. A.; PETERSON, N. D.; FEAGA, H. A.; KEILER, K. C. \& BAUGHN, A. D. Anti-tubercular Activity of Pyrazinamide is Independent of trans-Translation and RpsA. Scientific Reports, v. 7, n. 1, p. 1-8, 2017. Disponível em: <https://www.nature.com/articles/s41598-017-06415-5.pdf>. doi: 10.1038/s41598-01706415-5. 
KHAN, M. T.; KHAN, A.; REHMAN, A. U.; WANG, Y.; AKHTAR, K. et al. Structural and free energy landscape of novel mutations in ribosomal protein $S 1$ (rpsA) associated with pyrazinamide resistance. Scientific reports, v. 9, n. 1, p. 1-12, 2019. Disponível em: https://www.nature.com/articles/s41598-019-44013-9\#Tab2>. doi: 10.1038/s41598-01944013-9.

KOLLMAN, P. A. \& ALLEN, L. C. Theory of the hydrogen bond. Chemical Reviews, v. 72, n. 3, p. 283-303, 1972. Disponível em: <https://pubs.acs.org/doi/pdf/10.1021/cr60277a004>. doi: 10.1021/cr60277a004.

NIEMI, M.; BACKMAN, J. T.; FROMM, M. F.; NEUVONEN, P. J. \& KIVISTÖ, K. T. Pharmacokinetic interactions with rifampicin. Clinical Pharmacokinetics, v. 42, n. 9, p. 819-850, 2003. Disponível em: <https://link.springer.com/article/10.2165/00003088200342090-00003 >. doi: 10.2165/00003088-200342090-00003.

Organização Mundial da Saúde. Guidelines for the programmatic management of drug-resistant tuberculosis-2011 update. Disponível em: < https://apps.who.int/iris/bitstream/handle/10665/44597/9789241501583 eng.pdf>. Acesso em: 06 ago. 2021.

Organização Mundial de Saúde. HOW many TB cases and deaths are there?. 2018. Disponível em: <https://www.who.int/gho/tb/epidemic/cases_deaths/en/>. Acesso em: 15 set. 2019.

Organização Mundial de Saúde. TUBERCULOSIS. 2016. Disponível em: <https://www.who.int/health-topics/tuberculosis\#tab=tab_1>. Acesso em: 09 set. 2019.

PRAKASH, R.; GUPTA, R.; KATOCH, V. M. \& TIWARI, P. K. Molecular modelling and docking analysis of katG and rpoB gene in MDR-TB isolates from North Central Indian population. Journal of infection and public health, v. 10, n. 5, p. 593-599, 2017. Disponível em: <https://www.sciencedirect.com/science/article/pii/S1876034117300059\#tbl0015>. doi: 10.1016/j.jiph.2017.01.005.

SANNER, M. F.; OLSON, A. J. \& SPEHNER, J. C. Reduced surface: an efficient way to compute molecular surfaces. Biopolymers, v. 38, n. 3, p. 305-320, 1996. Disponível em: $<$ https://onlinelibrary.wiley.com/doi/10.1002/(SICl)10970282(199603)38:3\%3C305::AID-BIP4\%3E3.0.CO;2-Y>. doi: 10.1002/(SICI)10970282(199603)38:3\%3C305::AID-BIP4\%3E3.0.CO;2-Y.

SHARMA, D. \& BISHT, D. M. Tuberculosis hypothetical proteins and proteins of unknown function: Hope for exploring novel resistance mechanisms as well as future target of drug resistance. Frontiers in Microbiology, v. 8, n. 465, p. 1-5, 2017. Disponível em: <https://www.frontiersin.org/articles/10.3389/fmicb.2017.00465/full>. doi: 10.3389/fmicb.2017.00465. 
SRIVASTAVA, G.; TRIPATHI, S.; KUMAR, A. \& SHARMA, A. Molecular investigation of active binding site of isoniazid (INH) and insight into resistance mechanism of S315TMtKatG in Mycobacterium tuberculosis. Tuberculosis, v. 105, p. 18-27, 2017. Disponível

em: <https://www.sciencedirect.com/science/article/abs/pii/S1472979216304887?via\%3Dihu b>. doi: 10.1016/j.tube.2017.04.002.

STERLING, T. \& IRWIN, J. J. ZINC 15-ligand discovery for everyone. Journal of chemical information and modeling, v. 55, n. 11, p. 2324-2337, 2015. Disponível em: < https://pubs.acs.org/doi/10.1021/acs.jcim.5b00559>. doi: 10.1021/acs.jcim.5b00559.

TAO, X.; HUANG, Y.; WANG, C.; CHEN, F.; YANG, L. et al. Recent developments in molecular docking technology applied in food science: a review. International Journal of Food Science \& Technology, v. 55, n. 1, p. 33-45, 2020. Disponível em: <https://ifst.onlinelibrary.wiley.com/doi/abs/10.1111/ijfs.14325>. doi: 10.1111/ijfs.14325.

TROTT, O. \& OLSON, A. J. AutoDock Vina: improving the speed and accuracy of docking with a new scoring function, efficient optimization, and multithreading. Journal Computational Chemistry, v. 31, p. 455-461, 2010. Disponível em: < https://onlinelibrary.wiley.com/doi/abs/10.1002/jcc.21334>. doi: 10.1002/jcc.21334.

UNISSA, A. N.; SUBBIAN, S.; HANNA, L. E. \& SELVAKUMAR, N. Overview on mechanisms of isoniazid action and resistance in Mycobacterium tuberculosis. Infection, Genetics and Evolution, v. 45, n. 1, p. 474-492, 2016. Disponível em: <https://www.sciencedirect.com/science/article/abs/pii/S1567134816303872?via\%3Dihu b>. doi: 10.1016/j.meegid.2016.09.004.

ZHANG, L.; ZHAO, Y.; GAO, Y.; WU, L.; GAO, R. et al. Structures of cell wall arabinosyltransferases with the anti-tuberculosis drug ethambutol. Science, v. 368, p. 6496, p. 1211-1219, 2020. Disponível em: <https://science.sciencemag.org/content/368/6496/1211.abstract>. doi: 10.1126/science.aba9102.

YANG, J.; LIU, Y.; BI, J.; CAI, Q.; LIAO, X. et al. Structural basis for targeting the ribosomal protein $\mathrm{S} 1$ of Mycobacterium tuberculosis by pyrazinamide. Molecular Microbiology, v. 95, n. 5, p. 791-803, 2015. Disponível em: <https://onlinelibrary.wiley.com/doi/full/10.1111/mmi.12892>. doi: 10.1111/mmi.12892. 